\title{
The Sociolinguistics of Alternate Sign Languages of Arnhem Land
}

\author{
Marie Carla Dany Adone ${ }^{123}$ \& Elaine Lawurrpa Maypilama ${ }^{2}$ \\ University of Cologne ${ }^{1}$, Charles Darwin University² \& Australian National University ${ }^{3}$ \\ danyadone@gmail.com
}

\section{Introduction}

A look at the research done so far on sign languages shows a focus on the so-called primary sign languages, i.e. sign languages that are acquired by Deaf people as their first language. There is a substantial amount of studies on sign languages around the world, e.g. AUSLAN in Australia, Deutsche Gebärdensprache (DGS) (German Sign Language) in Germany, and American Sign Language in the States. More recently we note a diversification in sign language research, with an increase in sign languages other than the ones found in Western countries. We have studies on Jamaican Sign Language (Cumberbatch 2012), Mauritian Sign Language, (Gebert and Adone 2006, Adone 2012), Bhan Khor Sign Language (Nonaka 2012), Kata Kolok (de Vos 2012), Desa Kolok (Marsaja, 2015) among others. In spite of some effort to diversify the field, still very little is known on alternate sign languages. As these sign languages are underrepresented and under-documented in the field, we aim at providing some insights into these languages.

This paper is organized as follows. In section two we attempt at distinguishing the various types of sign languages. In section three we give an overview of the sign languages in Arnhem Land as reported in the past and present. Section four describes the sociolinguistic contexts in which these alternate sign languages are used. Section five discusses some linguistic features shared by these alternate systems. Section six provides a brief conclusion and some thoughts for future research.

\section{Classification of Sign Languages}

Based on the ongoing discussion in the field of sign language research we find many types of sign languages. One major distinction is between primary and alternate sign languages. Kendon (1988) proposed this distinction to do justice to sign languages acquired as first languages as compared to those that are used as an alternative mode of communication. However, this distinction presupposes that these two types are separate types. Primary refers to the first language, while alternate is used as an alternative to speech under special circumstances (Kendon 1988). This implies the language is learnt as a second language. This is obviously not always the case. A close look at some of the alternate sign languages in Arnhem Land and how/when they are used reveals that in some communities hearing people acquire these sign languages from birth, thus making the hearing population bimodal bilingual and not second language users of sign languages. 
Table 1 is an attempt to classify the various types of sign languages that have been reported in the literature so far.

Table 1: Preliminary Classification of sign languages

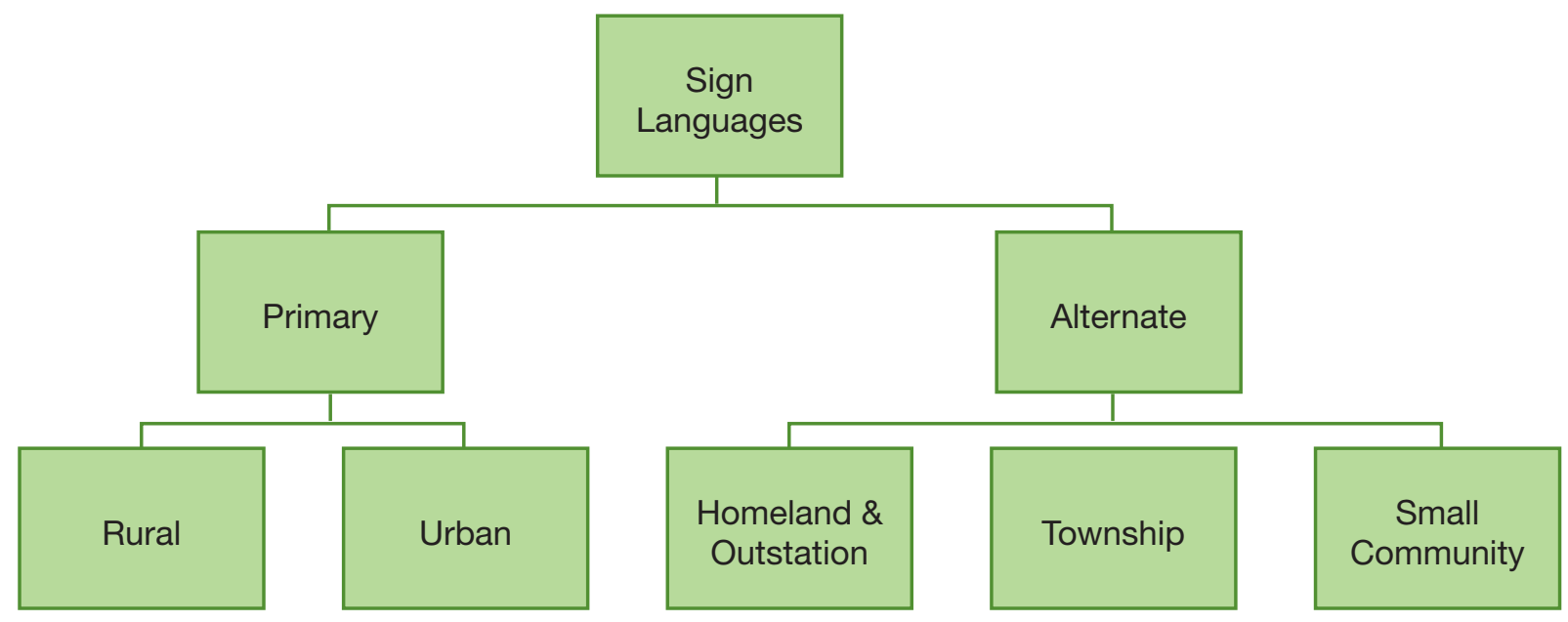

Source: Data collected by Adone and Maypilama in several communities in Arnhem Land

This classification is based solely on sociolinguistic grounds specific to the Australian context. Under "alternate" sign languages as used in Arnhem Land, Australia we find a three-way distinction. Whether these categories, are relevant for the sign languages in Central Australia, remains to be determined. One should note this table is by far not complete as the classification represents work in progress and is open to modification as we learn more about alternate sign languages.

Under "homeland and outstation" we classify sign languages found in those small settlements with small groups of people usually belonging to one or two families and their close kin. These settlements on clan territories are called 'homeland centers' or 'outstations' and are found throughout the remote areas of Arnhem Land. Life on homelands are organized more tightly around "landownership and care for sites family and ancestral connections" (James 2014:22), as such people on outstations live a more traditional life than in townships. On Elcho Island for example, Dayeri and Gawa are two such outstations. Around Gunbalanya we found approximately 13 outstations. We include the sign language variety used on outstations because we found some differences when comparing them to the sign languages found in townships. Such a difference is seen in the use of different signs or older signs. For instance, there are at least two signs for 'telephone', one of which is older and is used by old members of the outstations. Another example is seen in the sign for 'cats in the cradle' games which is a game children used to play with string made from shredded bark string (for example) to form shapes representing local locations, animals, objects. During an elicitation task, many young adults (25-30 years of age) living in townships, were not able to give us the signs for some cultural artifacts/knowledge such as 'string bag' or celestial bodies. In contrast, most old people on outstations knew these signs. This type of observation reinforces our view that outstations have possibly retained some 'old' signs that are either not commonly used anymore or have been replaced by other signs in the township sign languages, a possible scenario given that townships are the result of the government sponsored mission project to end nomadism among people over their land. 
Under "townships" we count Maningrida, Galiwin'ku, Minjilang etc. These are large settlements of 1000 people or more that have been developed by the government. In these townships we find several groups of Aboriginal people, sometimes from widely separate linguistic and geographical groups, living in close quarters with others, and with some usually poor facilities such as a shop, petrol station, police station, school, and maybe an airport. Under "small community" we would count Gapuwiyak, among others, which stand in between townships with smaller populations and outstations. Outstations generally have very few facilities but life there is less crowded and more pleasant.

\section{Overview on Sign Languages in Arnhem Land: Past and Present}

A look at reports on sign languages in Australia shows several scholars mentioning the use of sign languages across Arnhem Land, including Warner (1937) on Murngin Sign Language (also known today as Yolnu Sign Language), Folesche (1886) on Larrakia Sign Language, Priest (1986) on Tiwi Sign Language, and Bani (1981) on Torres Strait Island Sign Language.

Based on a more recent study on the sign languages in Arnhem Land (Adone 2014, Adone \& Maypilama 2014b), we find sign languages such as Yolnu Sign Language (henceforth YSL) as used in Milingimbi, Yirrkala and Galiwin'ku, or the sign language used by Burrara people in Maningreda to be structurally quite elaborate. At this point we cannot establish yet whether the sign language used by Iwadja speakers and Bininj Gun wok speakers (Croker Island) and the one used in Gunbalanya by Kuwinjku speakers are also structurally elaborate. However, based on some preliminary work done by Adone (2014), it seems in some places the sign language is highly developed in the sense it is used in a wide range of contexts, has a large lexicon (more than 1000 signs) and has complex constructions, while in other places they might not be or alternatively they might have lost some of their complexities.

One factor these sign languages all share is they are endangered languages, with varying degree of endangerment. We will not discuss the degree of endangerment of these languages in this paper as it would go beyond the scope of this article, however Adone \& Maypilama (2013) provides some information.

Map 1 gives an overview of some communities in Arnhem Land which we have observed the use of sign languages. This map is not exhaustive.

Map 1: The use of sign languages in communities of Arnhem Land

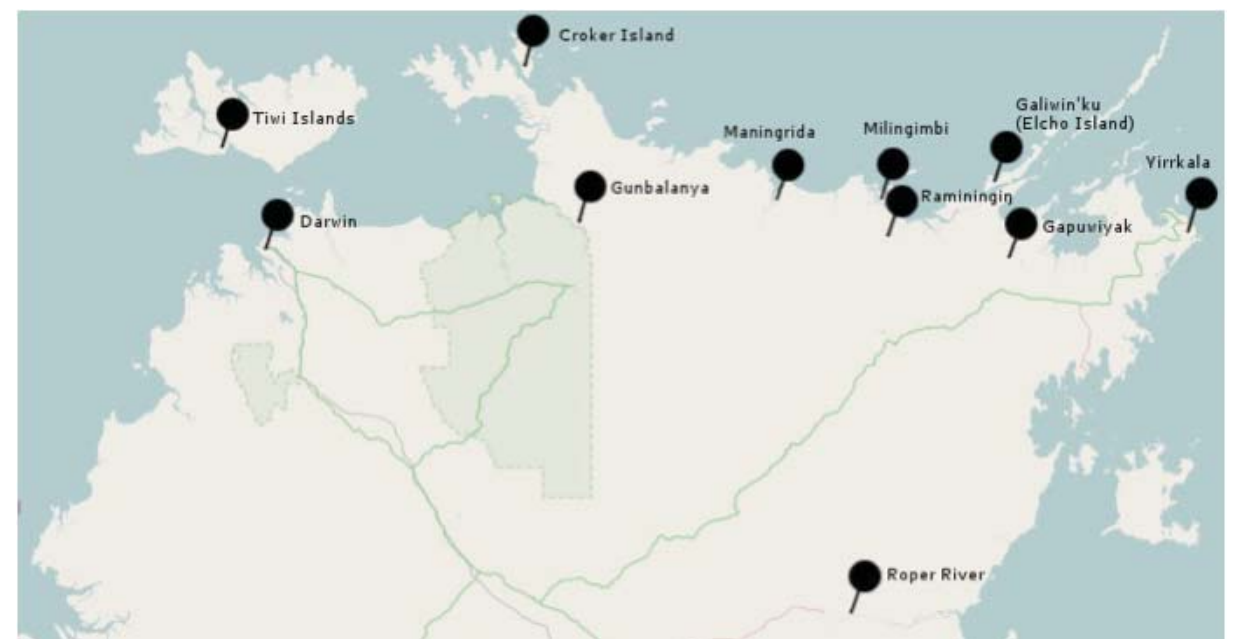

Source: (c) OpenStreetMap 
Around Darwin we have Larrakia Sign Language (henceforth LSL) that was reported by Folesche (1881). In 2012. Walsh (personal communication) mentioned the use of hand signs by some Larrakia Deaf people to one of the authors. Adone consulted the signs compiled by Caine and Reid (1997 on Tiwi Sign Language (henceforth TSL) and discussed the sociolinguistic data with Adam, a Tiwi man. In 2013 two language consultants Charly and Maggie in Minjilang, Croker Island, discussed the sociolinguistics of the sign language used by Iwadja people with Adone and Birch. In 2014 Andy and Donna, two high ranked Aboriginal people in Gunbalanya discussed the situation of the Kunwinjku people using sign language with Adone during her second visit in the community. In Maningrida a traditional elder who has now passed away provided Adone with the first information in 1996. More recently, Adone was able to discuss Burarra Sign Language (henceforth BSL) with Rebecca Green, one of the sign languages used in Maningrida. Data collection on Yolnu Sign Language in different locations (including Elcho Island, Milingimbi, and Yirrkala) started in 1992 and was endorsed by Elaine Maypilama, Kathy Gudjarak, Dorothee and other language consultants. Maypilama lives on Elcho Island and is one of the traditional owners of the place and Djambarrpuyngu, the language which belongs to Elcho Island. The data is naturalistic and elicited. Furthermore we have collected metalinguistic observations by members of the local communities.

\section{Sociolinguistic Characteristics of Alternate Sign Languages of Arnhem Land}

Map 1 shows the sign languages the authors encountered during their visits to these communities. Despite differences between the East and West Arnhem Land languages there are similarities in the social organization and the principles of interaction in all these language groups reflected in the sign languages.

First of all, all of these sign languages are used as a L1 by the few Deaf people living in the communities as well as by the members of the hearing community, thus making the hearing users of these sign languages bimodal bilinguals. In other words, the people use languages in two of the three modalities (visual, auditory and tactile) available to our species, namely speech and signs to communicate depending on the contexts. We will not include tactile modality in our discussion because of the lack of space. To the best of our knowledge, this environment in which speech and gestures and signs coexists is rarely attested elsewhere in the world with the exception of Native American communities (see Farnell 1995, 2003), but is very common in Aboriginal Australia. Two characteristics of this environment are: speech and gesture/signs are intertwined and used in parallel in conversations which has led to the so-called 'co-speech gesture situation' and the switch from speech to signs or vice versa which we label here as 'modality switching'. These two characteristics seem to be the key characteristics present in the context of alternate sign languages. The Yolnu communities can be taken as an excellent case. Both hearing and Deaf people acquire the language from birth onwards (Adone and Maypilama 2013). This might not be the normal case in all the communities of Arnhem Land nowadays. Several members of some West Arnhem Land communities (e.g. Gunbalanya and Minjilang) have expressed their concerns on this.

- For the hearing community these sign languages are alternate modes of communication they use in the following contexts:

- hunting, and fishing

- long distance communication

- $\quad$ ceremonies and rituals in which silence is culturally requested or speech is regarded as culturally inappropriate

- in the proximity of sacred objects 
- in time of mourning when the names of the deceased are not used and kinship signs are used among other devices to refer to the deceased

- in daily interaction when speech is effortful

In both hunting and fishing hand signs are used to communicate because noise would disturb the animals. However there are other activities in which sign language is also used, such as when walking in the swamps looking for mangrove worms. In this context it is important to use sign language because of crocodiles lurking in the swamp.

When people are not able to communicate through spoken language over long distance, sign language is usually used. This is seen in questions asked over long distance such as 'where are you going' or 'do you have a smoke for me'. People passing by in a car use sign language to ask for information such as 'river up or not'.

In various types of ceremonies, for example initiation ceremonies, novices use sign language because the use of spoken language is forbidden. We were also told that the male elders involved in the ceremony, for example. the ceremony 'bosses', also use sign language when they do not want to be overheard by the novices. Furthermore, communication in general, as well as some dances, are also performed with the use of sign language in funerals. Sign language is also used when on sacred grounds or close to sacred objects. These contexts have one common denominator: silence is culturally requested because speech is regarded as inappropriate.

In times of mourning, the name of the deceased is not used and reference to the deceased can only take place indirectly. This means that kinship signs showing one's relation to the deceased and other means of reference are used. There are differences among the various groups. Green (personalcommunication.) recalls that people announce the death of a person among the Burarra by sign language at a ritual called a hearing ceremony. This practice is confirmed among the Yolnu people (James 2014).

In daily interaction. such as talking at the same time as someone else, using speech and/or sign language may be used (see Maypilama \& Adone 2012, 2013).

At the beginning of this section we mentioned briefly the bimodal bilingual situation in which co-speech gestures/signs and modality switching seem to play a determining role in the sociolinguistic profile of alternate sign languages of Arnhem Land. Two further sociolinguistic factors associated with the use of alternate sign languages are shared knowledge, typical of small-scale communities, and circumspection. All these communities are remote and small in size, thus there is shared knowledge. Added to that, every member of the community is tied to other members through the kinship system. This state-of-affairs is reflected in the grammatical system, such as reference tracking. Circumspection is another factor that determines the use of alternate sign languages in these communities. As a highly valued principle in Aboriginal interaction (Levinson 2007, Garde 2008, Maypilama and Adone 2012) it motivates the use of discrete, concealed communication, which can be achieved by the use of signs.

\section{Some Structural Properties of Alternate Sign languages of Arnhem Land}

After a close look at the sociolinguistics we will briefly mention some of the structural properties that are typically shared by alternate sign languages studied here. There are four properties which we will briefly discuss here: the choice of non-manuals, variability, little morphology and iconic signs in compounds. All sign languages investigated so far, independent of their type, share four parameters (location, hand-shape, movement, orientation) for the articulation of an individual sign (for more details see Johnston and Schembri 2007). Furthermore, the use of non-manuals, for example facial expressions such as eye blinking, squinting, nose wrinkling, puffed cheeks, pouted lips, eye gazing, eye brow raising, mouthing and mouth gestures etc) is 
also important. Some of these facial expressions are commonly attested in many sign languages around the world. In some cases they share some common functions. Although there are some general tendencies in the use of non-manuals across sign languages, it seems the use of facial expressions is very much dictated by the culture in which these sign languages emerge. A piece of evidence in support of this view is provided by the use of eye gaze. While eye gazing is very common in many sign languages of the western world, eye gazing at people in the Aboriginal, especially in the Yolnu world, is not appropriate because it violates an important rule underlying Aboriginal interaction - respect for others and bidding for power. Thus, instead of eye gazing, we find eye pointing in cases where gazing is directed towards people. Eye pointing in this context is taken to be a very short look (of a few milliseconds) in the direction of the person referred to. In these cases, the signer's eyes move swiftly in the direction of the addressee and go back to its starting position or somewhere else for a very short time. At the same time, one uses lip pointing too as an additional means of reference.

Although thesealternatesign languages might havereached acertain level of conventionalization, there is high variability both on the macro- and micro-level of grammar. This is first and foremost attested in the use of space, when compared to the use of space in highly conventionalized and primary sign languages. The use of space in established sign languages is confined to a certain area as seen in picture 1 . This space "extends from approximately just above the head to the waist, and in width from elbow the arms are held loosely bent" as seen in pictures 2 and 3 (Brennan 1992:22). In the alternate sign languages studied here, signers exploit a larger space as seen in picture 4 in which a kin sign is used by touching one's calf.

Picture 1: Use of space in primary sign languages

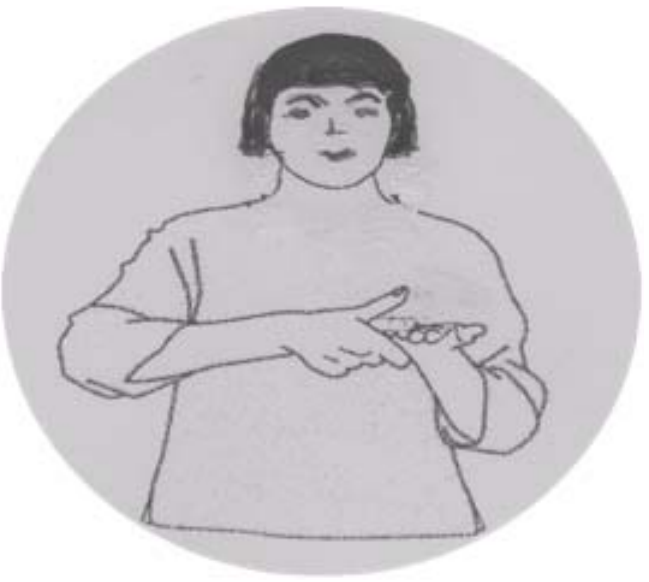

Picture 3: Pointing to an even further location

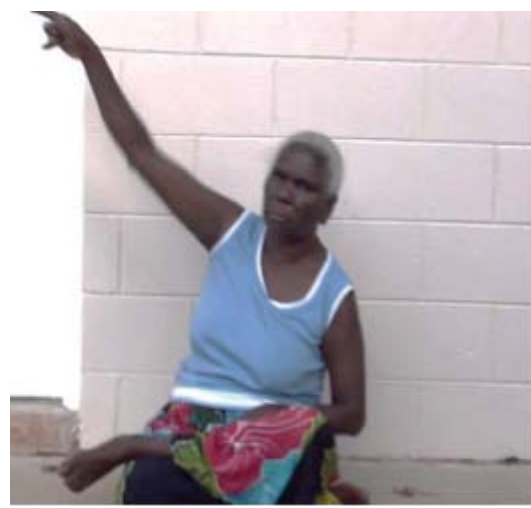

Picture 2: Pointing to a remote area

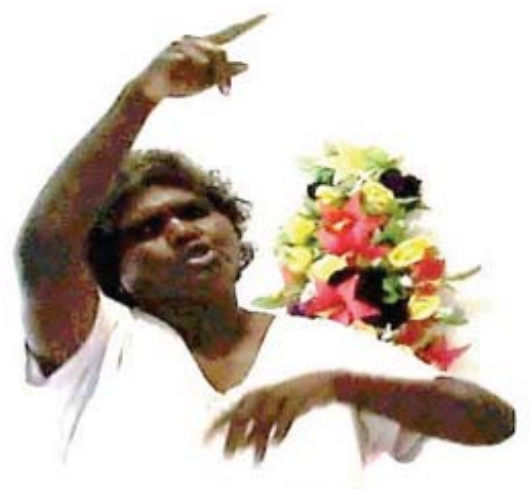

Picture 4: Sign for SIBLING

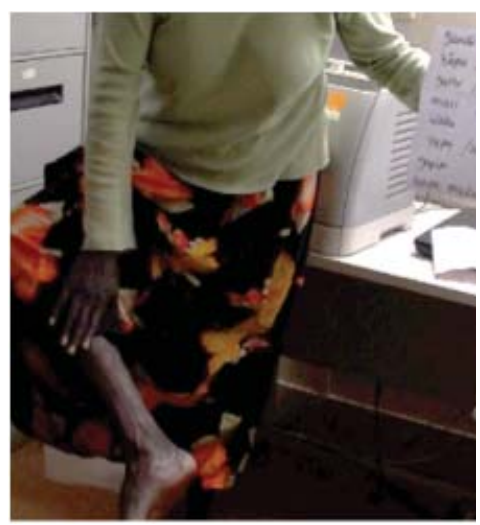


Although we cannot discuss the use of larger space in detail here, we would like to point to two factors that can account for this, namely that Aboriginal people use an Absolute Frame of Reference to refer to directions and locations, as well as direct pointing as a component of the pointing repertoire (Levinson 2003).

Further evidence for variability is seen in the use of signs such as UNCLE that is a combination of a hand-shape and movement as seen in picture (5). Some signers use the sign UNCLE with a short slap on the left hand, while others have their left arm standing vertical next to their body. The same type of variability is seen in many other signs including the sign for the dyadic relationship 'grandchildren-grandparents':

Picture 5a and 5b: Variability in the sign UNCLE (mother's side)
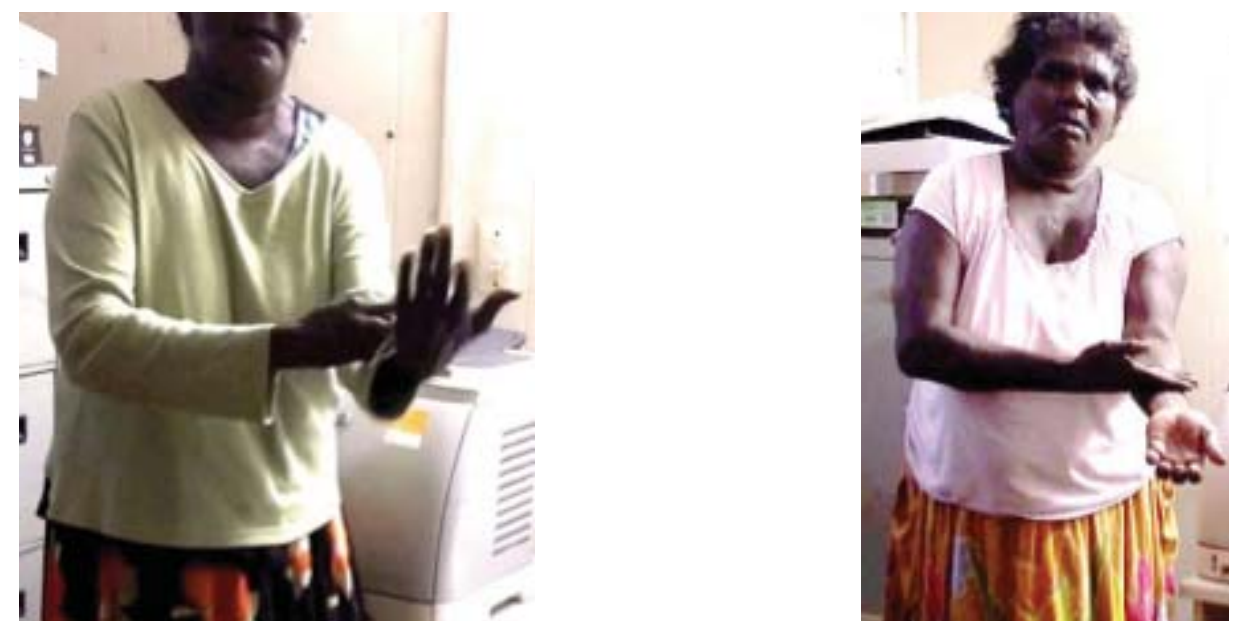

Picture 6a and 6b: Variability in the dyadic sign GRANDPARENTS-GRANDCHILDREN
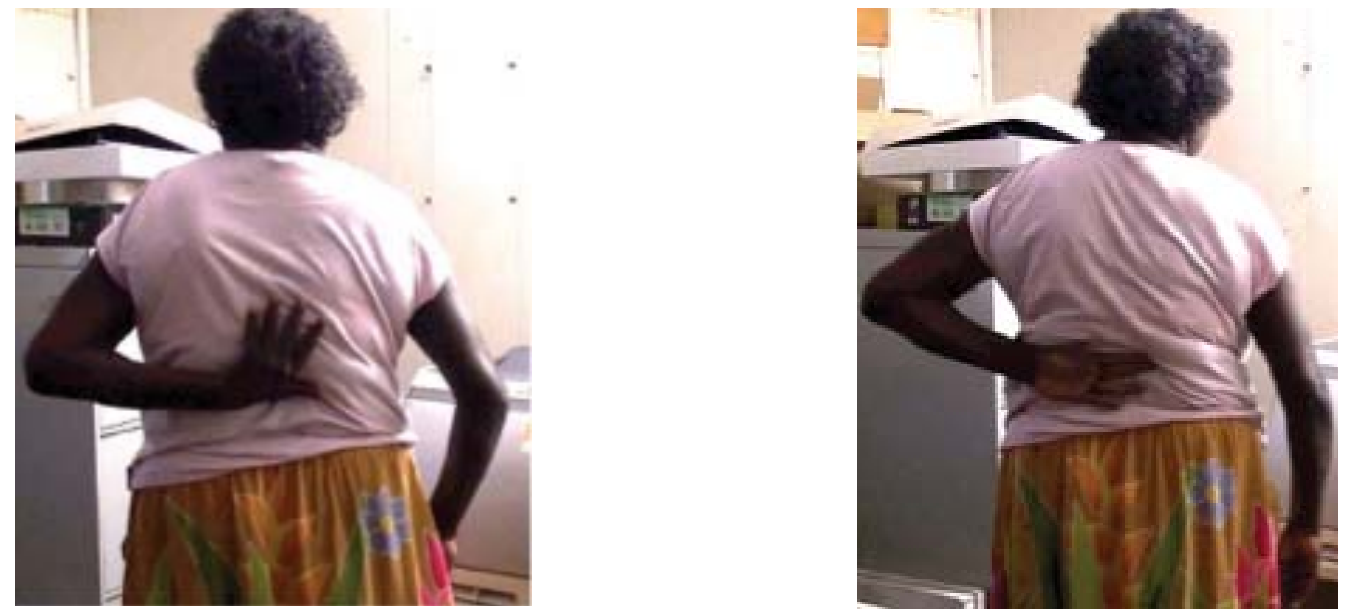
Another form of variability is attested syntactically, that is in the use of so-called non-manuals (e.g. facial expressions such as eye and lip pointing) that accompany manual signs to express some form of reference marking. As mentioned earlier, eye gaze is culturally not appropriate towards people, but eye pointing is. The two facial expressions, eye and lip pointing, are combined and used simultaneously with the verb 'fly' which is signed manually as in:

1) NGAPIPI YIRRKALA FLY FUNERAL

'My uncle is flying to Yirrkala for funeral'

when referring 'quietly' to someone in the surrounding area without attracting attention to the signer or the message passed on about the uncle. However both of these facial expressions are sometimes used on their own or are sometimes combined.

Picture 7: Eye pointing

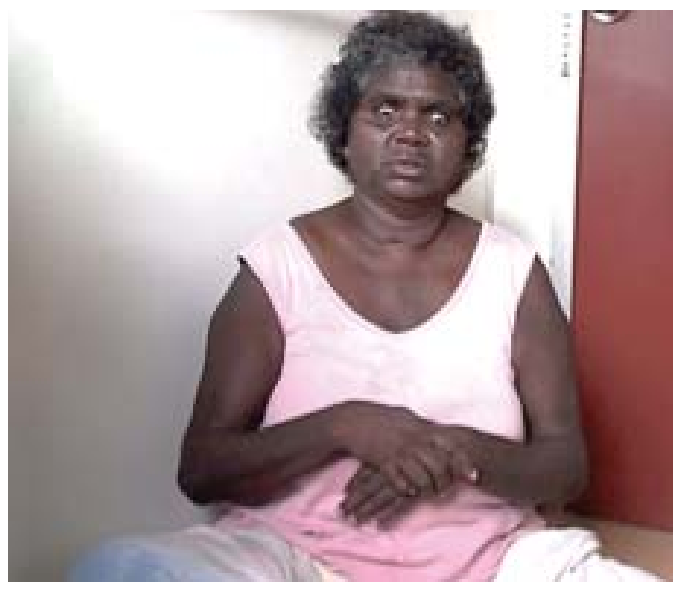

Picture 8: Lip pointing

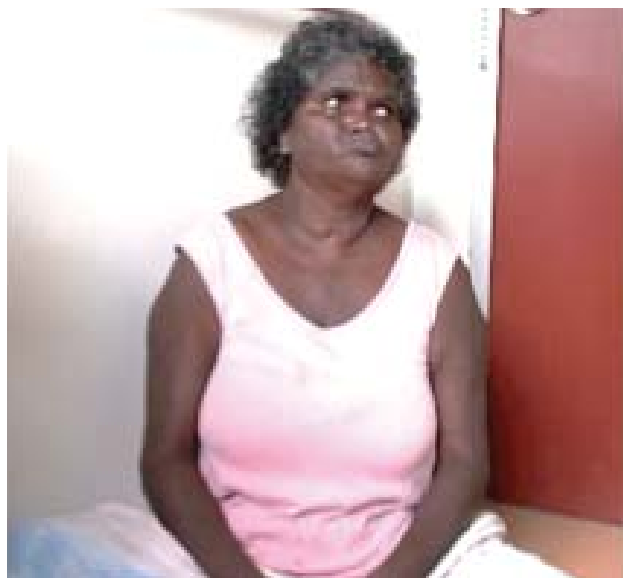

As compared to established sign languages, these alternate sign languages clearly show 'less' morphology. So far, we find the use of plain and directional verbs being attested, in contrast to established sign languages with a clear distinction between 'plain', 'directional' and 'agreement' verbs. Agreement usually marked by morphology is typically found in verbs such as 'give'. These verbs are expressed by little or no morphology. Some signers use 'give' as a directional verb only while others don't. In elicitation tasks, when asked to sign a sentence such as 'I gave a clap stick to three men', we have the verb GIVE signed by the movement of the hand departing from the signer's body towards referent 1 and returning to the signer's body. This movement is repeated three times in three different locations, accompanied by lip and eye pointing to mark locations of the referents. Other signers sign this sentence with one time movement departing from the signer's body towards one point in space and from there to another location etc. This is followed by the sign MAN referents and the sign THREE. Furthermore, we notice the sign CLAPSTICK is expressed as a separate sign instead of being 'incorporated' into the verb. 
In the area of derivational morphology we find compounds for non-Aboriginal signs consisting of two or three components such as in AIR CONDITIONER or WASHING MACHINE:

Picture 9: BOX COLD = AIR CONDITIONER
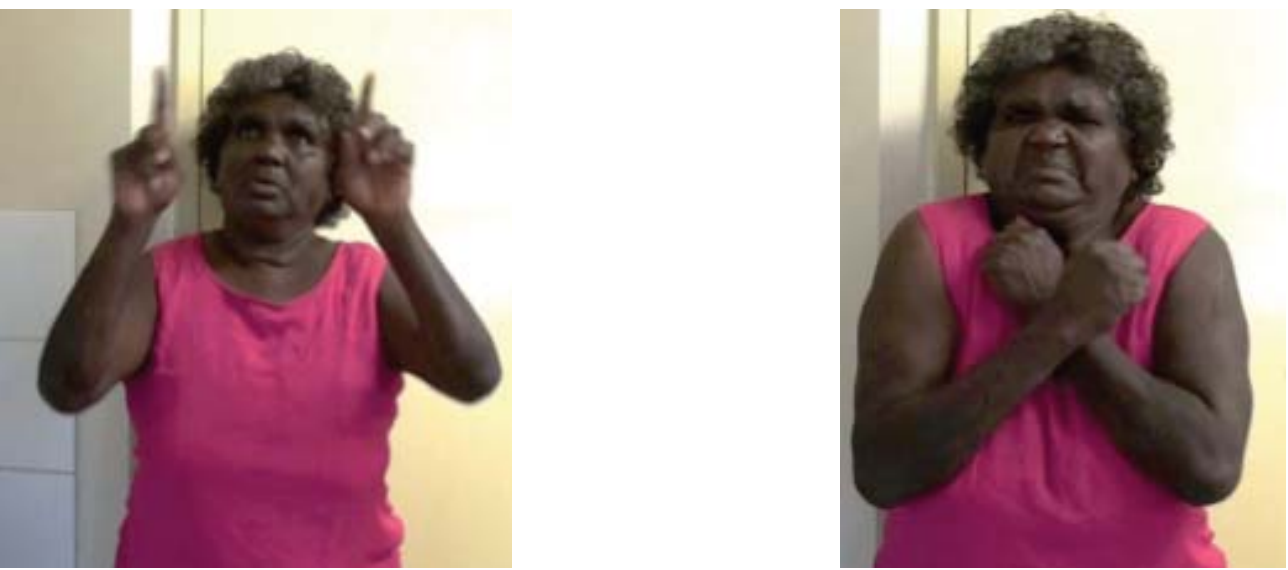

Picture 10: BOX WASH = WASHING MACHINE
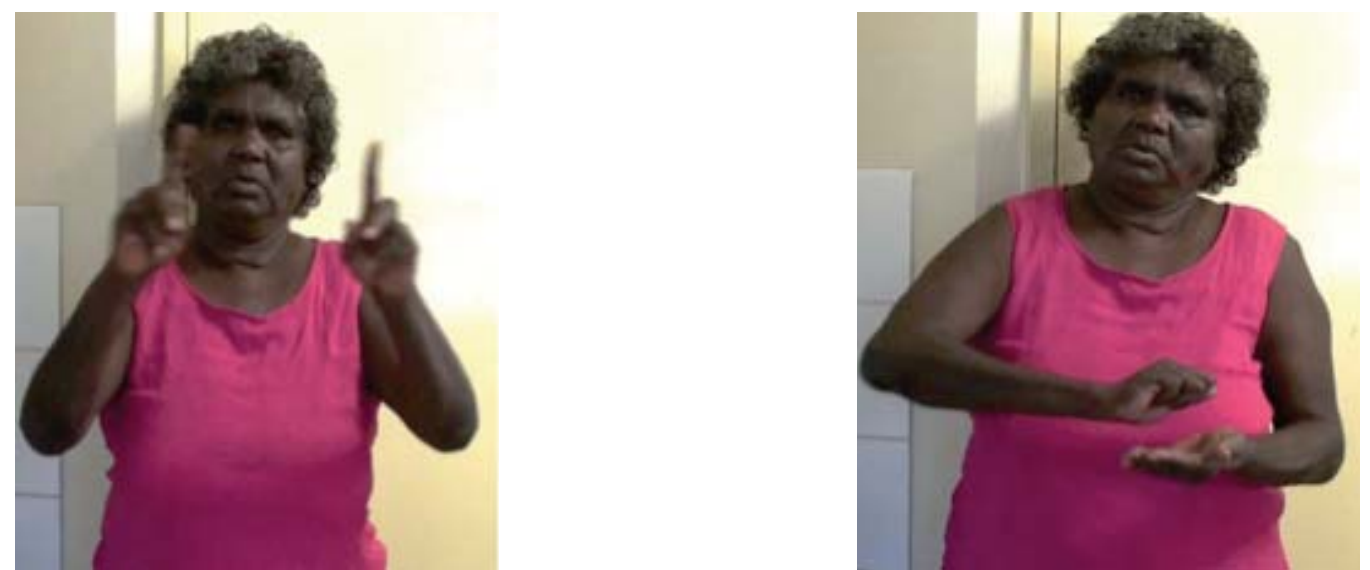

Signs for certain common activities such as 'sleep', 'eat', and 'dance' are iconic and shared across these alternate sign systems. An example is found in the same iconic minimal pair signs 'police' and 'in gaol' in YSL, KSL, and TSL:

Picture 11a: Sign for 'police'

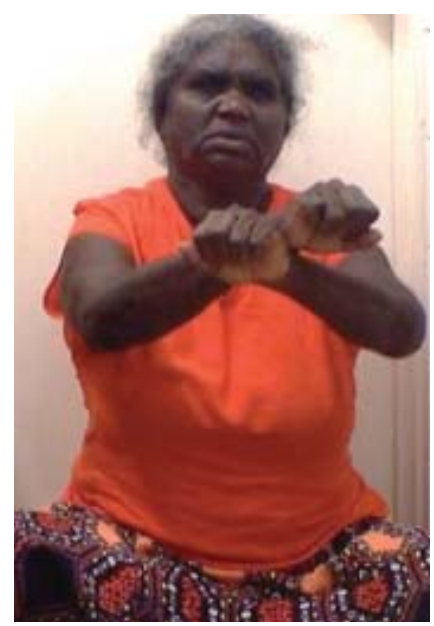

Picture 11b: Sign for 'in gaol'

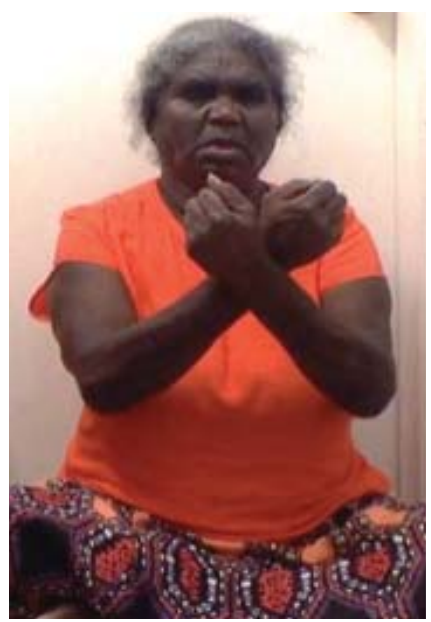




\section{Discussion}

A look at the literature shows two possible explanations for alternate sign languages in Australia. Kendon (1988) has argued that female speech taboo was probably one of the reasons for the emergence of alternate sign languages in the North Central Desert area of Australia, thus linking the existence of these sign languages to culture. Butcher (2015) argues that hearing impairment could account for the emergence of these alternate sign languages, thus linking the existence of the sign languages in Aboriginal Australia to Deafness. In the case of these sign languages under investigation here, we believe the cultural component, the request for silence/ the inappropriateness of speech in certain contexts (i.e. the proximity of sacred grounds, objects) as well as the underlying principle of circumspection in Aboriginal interaction account best for the existence of these sign languages. Further factors such as bimodal bilingualism being deeply rooted in the cultures with the effect of co-speech gestures/ signs and modality switching being the norm of interaction, can certainly not be overlooked. These factors play a key role in the sociolinguistic profile of alternate sign languages found in Arnhem Land. This is why we have taken a close look at the contexts of YSL, ranging from daily interaction to highly ritualized ceremonies.

We have found four properties that can be attributed to the alternate sign languages studied here: choice of non-manuals determined by cultural factors, variability, 'less morphology' and the use of iconic signs in the decomposition of compounds. As far as the non-manuals are concerned, it has become clear that the use of eye gaze in connection with people is not possible because it violates a crucial cultural rule. Thus, instead of eye gaze, we find eye pointing instead. Variability has been attested both on the lexical and syntactic level. On the lexical level, we found handshapes and location being affected. On the syntactic level, it is the use of accompanying non-manuals with signs to express grammatical relations. Eye and lip pointing normally occur in conjunction with each other, but sometimes they do not. 'Less morphology' refers to the fact that agreement seems to be absent in some contexts. Certain verbs require some agreement in order to make the argument structure clear. In most sign languages, some kind of agreement is used to do so. In these alternate languages, we find rudimentary forms of agreement, reminiscent of agreement marking in Creole languages (Adone \& Maypilama March 2014). A close look at compounds shows the existence of two or three iconic signs in the decomposition of compounds. Two excellent examples are the sign CITY that consists of three signs STONE BUILDING BIG and the sign GET MARRIED that consists of GRAB SILENT GO AWAY. In each example the signs stand next to each other (Kyle \& Woll 1985), a phenomenon already observed in the development of other sign languages.

\section{Conclusion}

In this paper we set out to discuss the sociolinguistics of alternate sign languages found in Arnhem Land. The alternate sign languages studied here share one sociolinguistic characteristic: they are used by small numbers of people in remote communities. They are all used by hearing and Deaf people. Although we have focused on the sign language used by the hearing people, we find that in many cases these languages are acquired from birth along with the spoken languages, thus making their population bimodal bilingual. Further, these alternate sign languages share some characteristics which might be typically found in Arnhem Land but not exclusively found in alternate sign languages. Further studies are required to establish a clear profile of alternate sign languages. 


\section{References}

Adone, D. (2012). Language emergence and creolisation. In R. Pfau, M. Steinbach \& B. Woll (Eds.), Sign language: An international handbook (pp. 862-889). Berlin: De Gruyter.

Adone, D. \& Maypilama, E. (2013). A Grammar Sketch of Yolngu Sign Language. Cologne: University of Cologne Press.

Adone, D \& Maypilama, E. (2014a). Alternate sign languages in Arnhem Land. Charles Darwin University. Unpublished Manuscript.

Adone, D. \& Maypilama, E. (2014b). Research Report: Bimodal Bilingualism in Arnhem Land. Australian Aboriginal Studies (AIATSIS). 2: 101-106.

Adone, D. 2014. Research Report: Indigenous Sign Languages of Arnhem Land. Australian Aboriginal Studies (AIATSIS), 1, 132-136.

Bani, E. (1981). Sign Language. Identity, 4(5), 19.

Brennan, M. (1992). The Visual World of BSL: An Introduction. In D. Brien (Ed.), Dictionary of British Sign Language/English (pp1-133). London and Boston: Faber \& Faber.

Butcher, A. (2015). The Origins of Alternate Sign Languages in Australia: could they Include Hearing Impairment?. Learning Communities: International Journal of Learning in Social Contexts, 16.

Cumberbatch, K. (2012). Sociolinguistic sketch of Konchri Sain. In U. Zeshan \& C. de Vos (Eds.), Sign Languages in Village Communities: Anthropological and Linguistic Insights (p. 387-388). Berlin: de Gruyter.

Caine, F.M. \& Reid, E. (1997). Tiwi hand signs: a teachers resource book. Nguiu, N.T.: Nguiu Nginingawila Literature Production Centre.

De Vos, C. (2012). Kata Kolok: an updated sociolinguistic profile. In U. Zeshan \& C. de Vos (Eds.) Sign Languages in Village Communities: Anthropological and Linguistic Insights (pp. 381-386). Berlin: de Gruyter.

Farnell, B. (1995). Do You See What I Mean?: Plains Indian Sign Talk and the Embodiment of Action. Austin: University of Texas Press.

Farnell, B. (2003). Sign Language, Indian. In S.I. Kutler (Ed.), Dictionary of American History (3rd edition) Vol. 7. (pp. 357-358). New York: Charles Scribner's Sons.

Foelsche, P. (1881/2). Notes on the Aborigines of north Australia. Transactions and Proceedings and Report of the Royal Society of South Australia, 5, 1-18

Garde, M. (2008). Person reference, proper names and circumspection in Bininj Kunwok conversation. In I. Mushin \& B. Baker (Eds.), Discourse and Grammar in Australian Languages (pp. 203-232). Amsterdam/Philadelphia: John Benjamins Publishing Company.

Gébert, A. \& Adone, D. (2006). A dictionary and grammar of Mauritian sign language. Vacoas, République de Maurice: Editions Le Printemps.

James, B. \& Baymarrwangga, L, (2014) The Yan-nhangu Atlas and Illustrated Dictionary of the Crocodile Islands. Sydney: Tein Wah Press.

Johnston, T. \& Schembri, A. (2007). Australian sign language (Auslan): an introduction to sign language linguistics. Cambridge: Cambridge University Press.

Kendon A. (1988). Sign Languages of Aboriginal Australia: Cultural Semiotic and Communicative Perspectives. Cambridge: Cambridge University Press.

Kendon, A. (2008). Some reflections on gesture and sign. Gesture, 8(3), 348-366. 
Kyle, J.G. \& Woll, B. (1985). Sign Language: The Study of Deaf People and Their Language. Cambridge: Cambridge University Press.

Levinson, S.C. (2003). Space in language and cognition: explorations in cognitive diversity. Cambridge: Cambridge University Press.

Levinson, S.C. (2007). Optimizing person reference - perspectives from usage on Rossel Island. In N. Enfield, \& T. Stivers (Eds.), Person reference in interaction: Linguistic, cultural, and social perspectives (pp. 29-72). Cambridge: Cambridge University Press.

Nonaka, A. (2012). Sociolinguistic sketch of Ban Khor and Ban Khor Sign Language. In U. Zeshan \& C. de Vos (Eds.), Sign Languages in Village Communities: Anthropological and Linguistic Insights (pp. 373-376). Berlin: de Gruyter.

Marsaja, G. (2015). Desa Kolok and its Deaf people. Learning Communities: International Journal of Learning in Social Contexts, 16.

Maypilama, E.L. \& Adone, D. (2012). Yolngu sign language: a sociolinguistic profile. In U. Zeshan \& C de Vos (Eds.), Sign Languages in Village Communities: Anthropological and Linguistic Insights (pp. 401-404). Berlin: de Gruyter.

Maypilama, E.L. \& Adone, D. (2013). Yolnu Sign Language: An Undocumented Language of Arnhem Land. Learning Communities: International Journal of Learning in Social Contexts, 13, 37-44.

Priest, C.A.V. (1986). Northern Territory Recollections. Benalla, Vic.: C.A.V Priest

Warner, W.L. (1937). A Black civilisation, a social study of an Australian Tribe. New York: Harper and Bros.

Wilkins, D. (2003). Why pointing with the index finger is not a universal (in sociocultural and semiotic terms). In S. Kita (Ed.), Pointing : where language, culture, and cognition meet (pp.171-215). Mahwah, N.J.: Lawrence Erlbaum Associates. 